\title{
A Comprehensive Solution to the Problem of the Development of Drawing Skills with the Help of Didactic Equipment
}

\author{
E.V. Vekhter ${ }^{1}$, V.Ju. Radchenko ${ }^{2}$, A. V. Shklyar ${ }^{3}$, T.D. Kazakova ${ }^{4}$ \\ vehter@tpu.ru|art@tomsk-7.ru| shklyarav@tpu.ru|.t.d2@mail.ru \\ 1,3,4 National Research Tomsk Polytechnic University, Tomsk, Russia; \\ ${ }^{2}$ Municipal budgetary institution of additional education «Art School», Seversk, Russia
}

\begin{abstract}
The authors of the article propose to use the didactic complex for morphological analysis in order to comprehensively solve the problem of drawing skills development at the beginning stage of training design students. This didactic complex includes visual didactic equipment and multimedia kit. In the course of the study general pedagogical methods were used: scientific and methodological literature analysis, pedagogical process planning, working methodology approbation. The project conception process was based on the system design methodology. The theoretical basis of the study is the works on the system design theory and the art education theory. The authors describe the requirements that the designer must take into account when designing didactic equipment; represent the structure of the didactic equipment and multimedia kit; offer options for working with elements of the didactic complex for morphological analysis.
\end{abstract}

Keywords: industrial design, drawing skills, visual skills, didactic tools, multimedia teaching tools, morphological analysis, system design.

\section{Introduction}

The problem of developing design students graphic skills is one of the modern education urgent problems in the design field. Academic drawing methods intended to professional artists training often turn out to be inaccessible for understanding of modern design students and do not always meet the objectives of training a designer. Thus, the purpose of this work is to find a comprehensive solution to the visual skills development problem of modern undergraduate students studying in the "Design" major at the initial stage (1-2 courses).

The object of this study is the visual skills development process during the design students training.

The subject of the study is didactic equipment as a mean of graphical and drawing skills development.

\section{Research methods}

In the course of the study general pedagogical methods were used: scientific and methodological literature analysis, pedagogical process planning, working methodology approbation. The project conception process was based on the system design methodology. The theoretical basis of the study is the works on the system design theory and the art education theory.

Under the visual skills in this work are understood formed by repeated repetition of the ability to visual activity, including:

1) technical skills that provide the ability of performing;

2) spatial thinking on which the ability to perceive is based;

3) artistic and imaginative thinking, which is the basis of the ability to creative work, to artistic expression.

Analysis of methods and techniques used in art education [5, $6,9,12,13$ and others] allowed to make a conclusion that all of them are based on the development of students ability to work with elements of a complex object: to see them, to isolate and transform (modify). It seems that these methods are primarily based on the ability of morphological analysis which is a method of the shape studying, design and the product parts relative location [3]. In this regard for the development of visual skills of designers at the initial stage of training in this study it is proposed to use such didactic equipment which will ensure the formation of stable skills of morphological analysis. Thus it is possible to assert that the development of visual skills with the help of such equipment will be more effective if it is presented as a real object (visual didactic equipment), and in online format (multimedia kit). The equipment provides reliability of visual perception and allows perceiving depth of space. Multimedia learning tools meet the modern young generation peculiarities of perception; allow increase students interest in learning process.

\section{The methodology of system design}

System design considers the object of design as a complex system that includes a variety of structural elements in one way or another connected to each other in a certain unity, integrity. Within the framework of system design, the designer approaches each object as a large and complex system which is at the same time an element of another system; takes into account the objects and phenomena that affect the system and which are affected by it. Parts of the considered system with system properties, which needs to be studied separately, create subsystems that, in turn, consist of minimal number of elements, indivisible components of the system. All elements of the system are united by stable horizontal and vertical connections that determine the system order.

The main principles of system design are: nonlinearity, multifactoriality; expediency; accessibility, democracy, relevance; consideration of many aspects of the problem in the decision-making process; comprehensive consideration of problematic issues; integrity of the problem coverage; identification and consideration of relationships between parts of the problem; unification of figurative and project; social quality trend.

During designing an object design as a system it is necessary to proceed, first of all, from the goals and functions of the designed object; to take into account its external relations with other objects; to assume the consequences of the decisions impact regarding the designed object on all related systems.

In accordance with the principles of system design, the object of design should be anthropocentric, multicomponent and multilevel, open and flexible, self-organization and selfdevelopment, manageability, activities inclusion [7].

In the system approach, the object of design is considered as a complex system consisting of three main subsystems: users, environment, tools [7]. These three components influence design decisions: the designer must focus on users, consider the impact of the environment on the object and the impact of the object on the environment, plan the means for the production of the design product. In this study, when designing didactic equipment, these subsystems are considered more widely: the subsystem "society "(users), the subsystem "ecology"(environment), the subsystem "economy" (means).

Subsystem "society" includes the following elements:

1) need (need to improve didactic equipment for use in art education at the initial stage of training);

2) possibility (availability for the user); 
3) psychological properties of the person (requirements to training of designers, requirements to the didactic equipment, the account of features of visual perception).

The subsystem "environment" includes the following elements:

1) production (should not adversely affect the environment);

2) operation (working with the kit must be safe, the kit must not adversely affect the environment);

3) materials (must be environmentally friendly);

4) disposal (must be environmentally friendly).

Subsystem "economy" includes the following elements:

1) demand;

2) sale;

3) materials (must be cost-effective);

4) production (should be simple and cost-effective);

5) pricing (combines all elements);

6) marketing.

Any designed object must meet aesthetic, functional, ergonomic, sociological, economic and environmental criteria.

\section{Didactic equipment requirements}

In addition to considered principles of system design the designer must take into account following requirements, while designing didactic equipment.

Sanitary standards, ergonomic requirements. Equipment intended for use in the educational process should be made of materials that have received a hygienic assessment and confirmed by a certificate. The edges of the connecting elements must be safe to use, must not have any gaps and sharp corners. The dimensions of the didactic equipment should correspond to its purpose and the psychophysiological capabilities of users [4, $11]$.

\section{Educational requirements.}

From a methodological point of view, didactic tools should correspond to the age of students and their developmental level. Visual tools used in the educational process should meet the goals and correspond to the course content; the amount of work with visual tools (the number of items of didactic equipment and the working time) should be reasonable [8, 14]. Visual tools should closely correspond to real objects, should be aesthetically designed and should not include unnecessary elements [10].

Consideration of psychological criteria. Being a visual tool, didactic equipment for training designers should correspond to the psychophysiological features of visual perception: it should provide the possibility of touch and movement (objectivity of perception), as well as reliable perception of the object dimensions. The design student's work with such equipment for them is the experience of professional perception of real objects, which ensures constancy and apperception. In the process of working with didactic equipment, it is necessary to form the selectivity of perception to develop a professional designer view.

Taking into account all of the specified requirements and principles in this research visual didactic equipment for morphological analysis was designed.

\section{Visual didactic equipment for morphological analysis}

The developed didactic equipment for morphological analysis consists of simple geometric shapes (modules) divided on the plane, which can be connected together with the metal rods, thus forming various complex multi-level shapes (Fig. 1.).

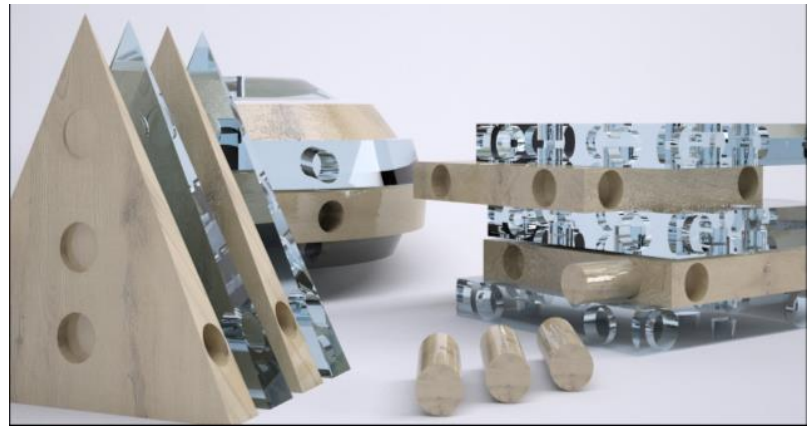

Fig. 1. 3D model of didactic equipment elements for morphological analysis.

The didactic equipment for morphological analysis includes the following main elements (modules):

1) 10 square wooden plates measuring $150 \times 150 \mathrm{~mm}$ and 10 of the same plates made of plexiglass;

2) 10 wooden plates in the shape of a hexagon of $150 \times 150 \mathrm{~mm}$ and 10 of the same plates made of plexiglass;

3) round plates of different diameter, folding into a ball (10 wooden, 10 plexiglass);

4) 20 round plates with a diameter of $150 \mathrm{~mm}(10$ - wooden, 10 - plexiglass), folding into a cylinder;

5) square plates of different sizes, folding into a pyramid (10 wooden, 10 plexiglass).

In each plate on all sides cut five through holes for the rod (metal solid pin).

Figure 2 demonstrates equipment components examples.
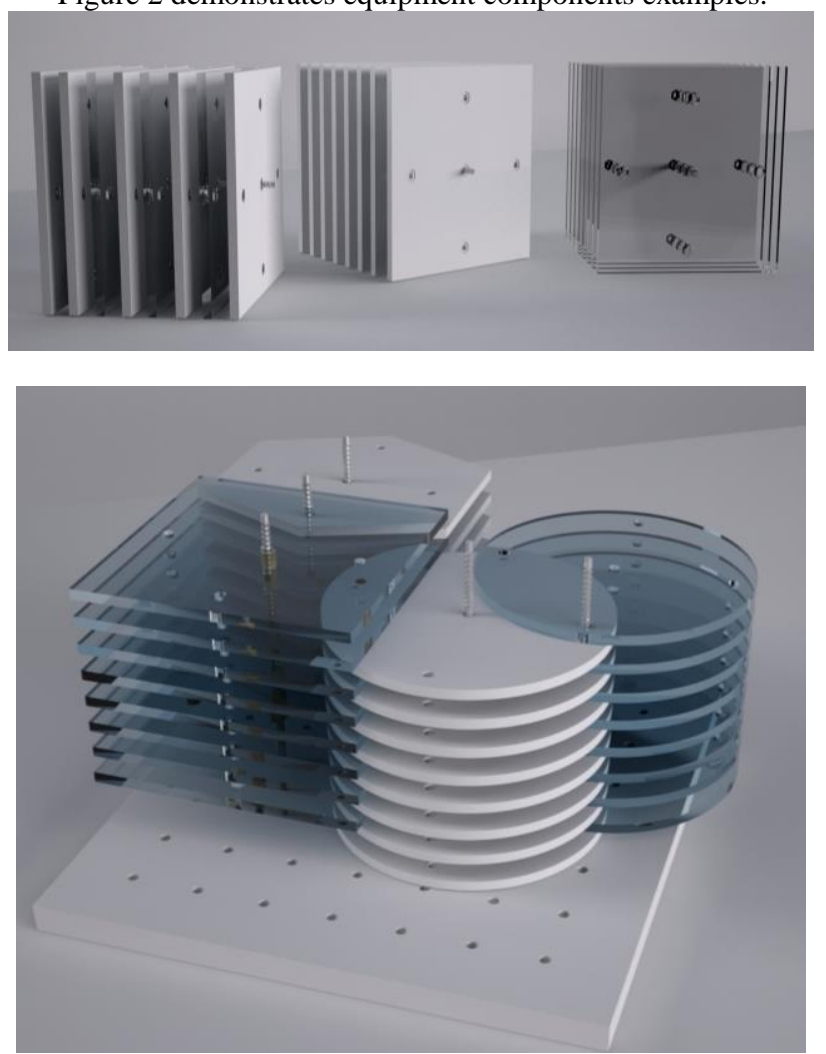

Fig. 2. Elements of didactic equipment/

The equipment includes an additional part that allows to locate the modules relative to the stud at different levels. This part is a rectangle $150 \times 14 \times 10 \mathrm{~mm}$ with rounded corners. It has 10 holes in the shape of a hexagon with glued nuts.

Figure 3 shows a photo with one of the assemble option of the equipment with an additional part. 

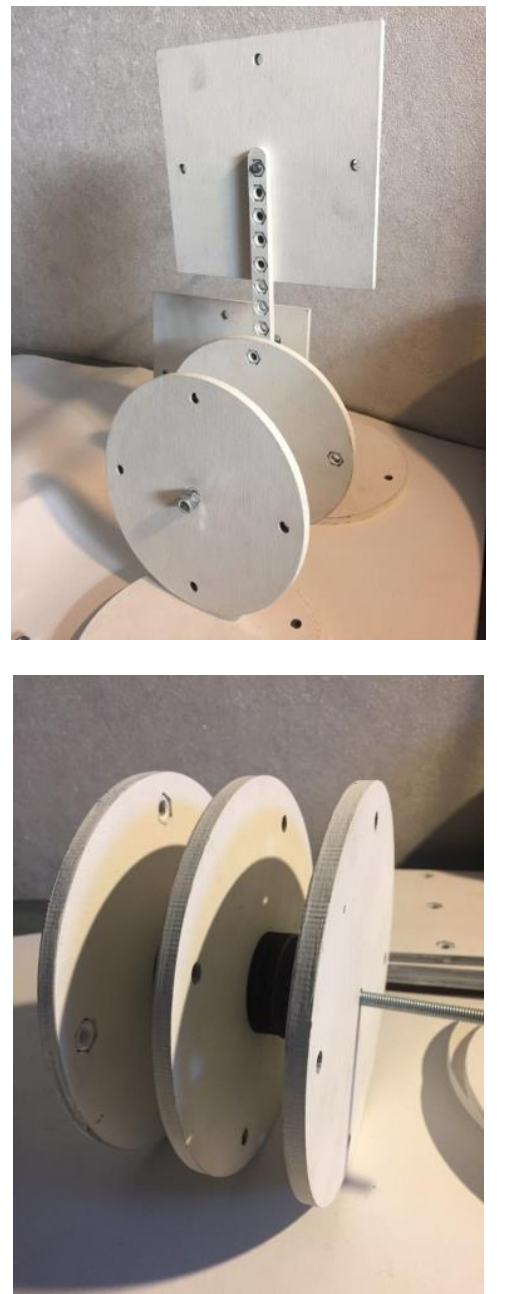

Fig. 3. Assembly with additional fastening detail.

The final element of the equipment is fixing base $(190 \times 172$ $\mathrm{mm}$ ), made of plywood with a thickness of $20 \mathrm{~mm}$. Across the surface of the base evenly distributed through holes for pins (Fig. 4).

A metal weighting device can be attached to the base.

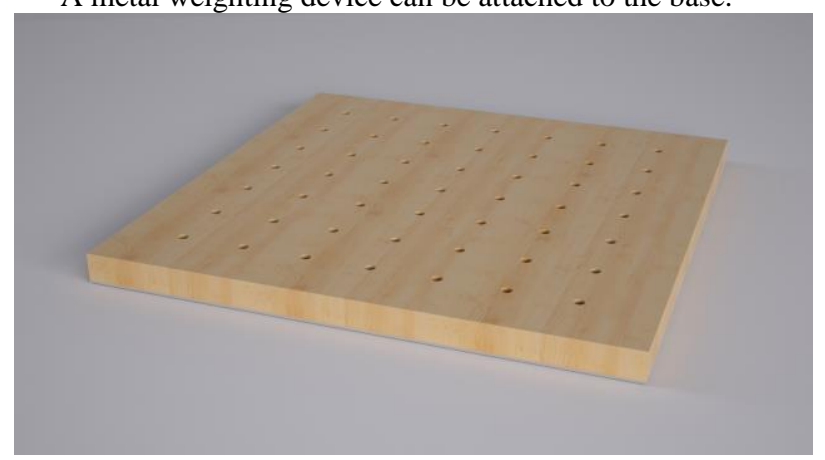

Fig.4. Fixing base.

This didactic equipment is intended to be used as a visual tool for drawing: the modularity of the kit allows to create a variety of shapes - from simple (cube, pyramid, sphere, cylinder, and prism) to complex imaginary invented shapes.

Due to the shape, structure and material, the developed didactic equipment for morphological analysis provides design students with the following opportunities to develop visual skills, in particular spatial thinking:

1) to see the object from different sides;

2) to sense material and volume;

3) to perceive both the integral volume of the geometric body and the frame shape;

4) to see the parts of geometric body relative position;
5) to create different shapes consisting of the same shape modules;

6) to create different shapes consisting of different shapes modules.

From the methodological point of view, advantages of the developed didactic equipment are the ability to organize both individual and group work (due to the selected size of the equipment), as well as the ability to complicate tasks by adding / removing modules that make up the main figure.

Further, taking into account modern trends in education, the developed visual equipment was transferred to electronic visual environment in the format of a multimedia kit for morphological analysis.

\section{Multimedia kit for morphological analysis}

The structure of the proposed multimedia didactic kit for morphological analysis is represented by two main elements: videos that allow to demonstrate and explain the material, and a package of interactive tasks the purpose of which is to train visual skills in a virtual environment and assess the degree of their formation (for more information about the multimedia kit composition refer to [2]).

The tasks of the interactive package contain a set of elements for morphological analysis formed by the teacher (for example, to make a composition of 14 round, 7 square, 7 prismatic plates (Fig. 5)).

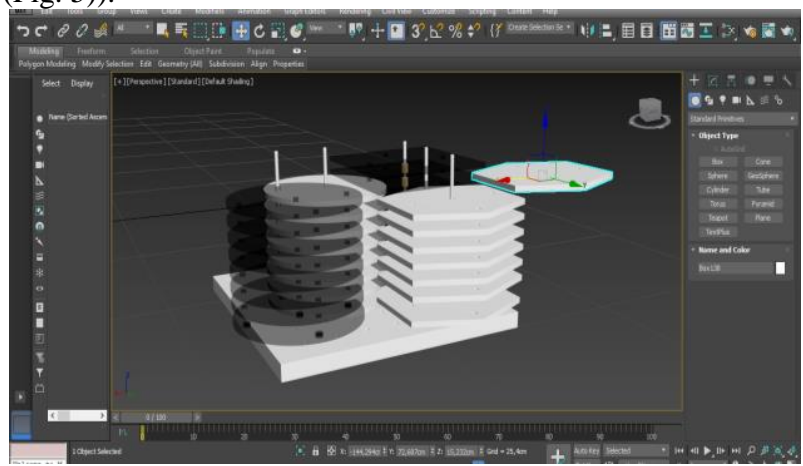

Fig. 5. An example of an interactive task.

Based on the proposed set, students independently develop their own version of the composition (configuration of elements).

Due to this type of tasks, students in a convenient and familiar form (in a virtual environment) train the technique of composition construction. Regular solution of creative tasks on composition ("formal tasks" [1]) provides formation of designer professional thinking.

\section{Conclusion}

Thus, in order to comprehensively solve the problem of design students visual skills development at the initial stage of training, this study developed the concept of a didactic complex for morphological analysis.

Designed in this research didactic system for morphological analysis aims to resolve the contradiction between the need of owning sustainable graphic skills (technical skills, spatial and artistic creative thinking), on the one hand, and the lack of innovative teaching equipment to effectively develop these skills at the initial stage of education of design students on the other hand.

The use of system design methods in the design process of didactic equipment allowed to develop a design object that meets all modern requirements, effectively performs its functions, characterized by innovation.

Innovativeness of the developed object is caused by the following factors:

1) novelty of the proposed solution-the proposed didactic equipment combines the strengths of the currently existing 
visual materials, additionally is characterized by complexity, modularity, compactness, versatility;

2) practical value-the use of the didactic complex will increase the level of art education;

3) transfer of didactic equipment to the virtual environment, which meets the modern trends of education computerization, the use of electronic educational resources in the educational process;

4) a combination of different ways of work with the complex: tactile (didactic equipment), visual (videos), interactive (performing tasks on the computer).

Work with the complex is based on the principles of complexity, consistency and consistency. The developed complex takes into account the identified shortcomings of classical didactic equipment, corresponds to modern trends in education although is available and convenient for teachers and students. Didactic complex for morphological analysis presented in the form of visual equipment and multimedia kit, provides effective formation of design students visual skills.

Potential consumers of the developed didactic complex are art schools and universities, which train designers and architects. Didactic equipment is designed for classroom work in drawing classes. Multimedia kit can be used as a separate independent learning tool in the classroom and extracurricular work of design students, and part of the whole online course on the discipline "Propaedeutics" for students enrolled in the educational of bachelor "Design" program which will optimize the independent work of students, make students active subjects of learning process, as well as increase their motivation.

The didactic complex will allow to solve the following problems of visual skills development:

1) the development of spatial thinking, which has importance is particular not only for creative people, but also for all technical specialists;

2) development of artistic and imaginative thinking;

3) formation of designing skills on the basis of work with simple geometrical figures.

4) improvement of technical skills through regular copying of different shapes and compositions.

\section{References}

[1] Bakaldina G.V. Compositional shaping as a means of future designer professionalization at the initial stage of training at a university // Successes in modern science and education. 2017. - T. 1. - No. 2. - S. 6-8.

[2] Vechter E.V., Radchenko V.Y., Kazakova T.D. The concept of a multimedia didactic kit for morphological analysis in the training of design students // GraphiCon 2018: proceedings of the 28th Intern. conf. on computer graphics and machine vision. - Tomsk, 2018 .-- S. 348-349.

[3] Gorbunova T.G. Morphology as a method of analysis of material archaeological sources // Actual problems of the history of Siberia. Fifth Scientific Readings in Memory of Professor A.P. Borodavkina: Sat scientific tr / Ed. V.A. Skubnevsky and Yu.M. Goncharova. - Barnaul: Az Buka, 2005. - S. 249-250.

[4] GOST 25779-90. Toys General safety requirements and control methods (date of introduction: 01/01/1992).

[5] Znamenskaya E.V. The formation of spatial representations in primary school students in the study of geometric material: dis. ... cand. ped sciences. - M., 1995 .-- 201 p.

[6] Markov V.I. Heuristics in the development of the culture of spatial and spatial thinking // News of universities. Investments. Construction. The vend. - 2011. - No. 1. - S. 193-206.

[7] Mikheeva M.M. Fundamentals of system design: guidelines for the course "Fundamentals of Design Theory and
Methodology in Industrial Design". - M.: MSTU. N.E. Bauman, 2010 .- 59 p.

[8] Ostapenko I.A., Magomedova E.V. Didactic requirements for visual methods and their use in the process of teaching practice // Scientific and methodical electronic journal "Concept". - 2016. - T. 23. - S. 72-76.

[9] Beijing O.I. Didactics of art education: a prognostic methodology for planning educational content according to a drawing // TSU Vector Science. - 2015. - No. 2 (32-1). - S. 196-204.

[10] Sazonova M.V. Teaching and developing possibilities of didactic material, practical orientation of the lesson // Infourok. 04/09/2017. - URL: https://infourok.ru/metodicheskiy-material-obuchayuschie-irazvivayuschie-vozmozhnosti-didakticheskogo-materialaprakticheskaya-napravlennost-urokov-1771131.html (accessed: 02/10/2018).

[11] SanPiN 2.4.7.007-93. Production and sale of games and toys. Sanitary rules and norms (approved by Decree of the State Committee for Sanitary and Epidemiological Supervision of the Russian Federation No. 9 of August 12, 1993) (as amended on December 19, 2005, as amended on October 28, 2010).

[12] Chernyshev Y.V. On the problem of developing constructively spatial thinking of design students in the process of teaching design drawing // Science. Art. The culture. - 2015. - No. 2 (6). - S. 261-265.

[13] Shcheglov A.V. The role and place of volumetric-spatial composition in the training of design students // Bulletin of Tula State University. Humanitarian sciences. - 2012. - No. 1-2. - S. 351-358.

[14] Saljo R. Representational tools and the transformation of learning // Designing for Change in Networked Learning Environments. - Bergen, Norway, 2003. - T. 2. - R. 1-2. 